\title{
Study of FTO Gene Polymorphism Association with Type 2 Diabetes and Increasing BMI in Egyptian Patients
}

J.H.Sabry ${ }^{1}$, M.E.Ibrahim ${ }^{2}$, S.A.El Fadeel, A.A. El-Fallah ${ }^{1}$

${ }^{1}$ Clinical and Chemical Pathology Dept., Faculty of Medicine, Benha Univ., Benha, Egypt

${ }^{2}$ Internal Medicine Dept., Faculty of Medicine, Benha Univ., Benha, Egypt

E-Mail:ahmed2356@gmail.com

\begin{abstract}
The aim of this study is to demonstrate the association of the fat-mass and obesity associated gene (FTO) polymorphisms with type 2 diabetes (T2D) and the various aspects of BMI in Egyptian patients. FTO quality polymorphism was distinguished utilizing PCR-RFLP in 40 patients with type 2 diabetes mellitus (DM) and 40 evidently sound control subjects. All members were exposed to clinical assessment including estimating systolic and diastolic circulatory strain, BMI, midsection perimeter (WC), neck circuit (NC) and abdomen hip proportion (WHR) and evaluation of both quantitative insulin affectability check record (QUICKI) and HOMA-IR. People with AA genotype were 6.8 occasions bound to have DM than TT genotype patients. T allele was viewed as a defensive factor while An allele was a free hazard factor for T2DM. AA and AT genotypes are noteworthy indicators of type 2 diabetes mellitus. There was noteworthy increment in BMI, NC, WHR (in females) and WC (in guys) in AA genotype bunch contrasted with TT and AT genotype gatherings. HOMA-IR was distinguished higher in AA genotype bunch contrasted with TT and AT genotype gatherings. An allel of (FTO rs9939609) quality polymorphism was seen as altogether connected with expanded danger of T2D and expanded BMI in Egyptian patients.
\end{abstract}

Keywords: FTO gene, Type 2 diabetes, Gene polymorphism, BMI.

\section{Introduction}

Stoutness commonness among all age bunches is expanding all inclusive, particularly in the more seasoned populace $>65$ years. 1 Unless this emergency is forestalled, by 2030 more than 1 billion grown-ups are relied upon to be obese. 2 This will stay an enormous weight on the human services framework, not inferable from heftiness itself, yet because of conditions, for example, coronary illness, stroke, type 2 diabetes mellitus (T2D), tumors, and physical impairment [3].

Diabetes includes a gathering of hyperglycemic metabolic infections. The causes fluctuate from hypersensitive or metabolic variations from the norm to deserts in insulin creation and secretion [4].

Changes in way of life, for example, eating and exercise, or care with some enemy of diabetic meds impact the heftiness related markers, for example, BMI. Expanded corpulence commonness can be credited to evolving ways of life, a huge utilization of fatty food and diminished physical movement, yet hereditary components can likewise play a noteworthy role [5].

Various investigations reported that fat-mass and weight related quality (FTO) polymorphisms are firmly connected with stoutness and a significant hazard factor for type 2 diabetes (T2D) [6].

The basic rs9939609 polymorphism in the fat massand heftiness related (FTO) quality is related with higher $\mathrm{BMI}$, danger of weight, and resulting $\mathrm{T} 2 \mathrm{D}$ in various populations [7 ].

The human FTO quality is situated on chromosome 16q12.2 which comprises of 9 exons and ranges. Numerous investigates recorded connection between FTO SNPs and hazard factors for stoutness. One of the polymorphisms embroiled in stoutness and T2D is the rs9939609 FTO gene [8].

We planned to examine the relationship of the fatmass and stoutness assotiated quality (FTO) polymorphisms with type 2 diabetes (T2D) and its connection with BMI increment in Egyptian patients.

\section{Subjects and methods}

The examination was endorsed by the Ethics Committee of the Faculty of medication, Benha University. Educated concents for support were gotten from all members and the technique and potential dangers were clarified altogether, as per the Declaration of Helsinki.

The exploration was arranged as a case-control study led at the Department of Clinical and Chemical Pathology and Department of Internal Medicine at Benha University between November January 2018 and April 2019.

Medical clinic between January 2018 and April 2018. The 80 subjects an alyzed were isolated into two gatherings:

Forty patients ( 9 folks and 31 females) with diabetes mellitus type 2 who were broke down by the models set up by the American diabetes Association Expert Committee (confirmed fasting blod glucose N $126 \mathrm{mg} / \mathrm{dl}$ (7 mmol/l and also 2-h postprandial glucose level N 200 $\mathrm{mg} / \mathrm{dl}(11.1 \mathrm{mmol} / \mathrm{l})$ on more than occasion) (Expert Committee on the Diagnosis and Classification of Diabetes Mellitus (2003)), and 40 sound developed and sex composed subjects filling in as a benchmark bunch were tried the examination.

Patients developed some place in the scope of 42 and 70 years with BMI > $25 \mathrm{~kg} / \mathrm{m} 2$ and all were on oral hypoglycemic. Patients with liver contamination, danger, diabetes-related monogenic issues and patients tolerating insulin or remedies that could raise glucose levels were removed from the examination.

Forty clearly solid age-and sex-composed individuals ( 24 females and 16 folks) developed 41 to 70 years were filling in as control gathering. They were freed from 
Type 2 DM family lineage and with HbA1C regard < $6.0 \%$.

All individuals were experienced full history and clinical overview, including: systolic and diastolic BP. Anthropometric estimation: BMI, NC, WC and WHR.

\section{Sample collection}

Five mls of venous blood were collected from each participants after overnight fasting and divided into two parts:

- First part: Two mls on EDTA, ethylene-diamine tetra-acetic salt $(1.2 \mathrm{mg} / \mathrm{mL})$ as an anticoagulant, were used to evaluate $\mathrm{HbA1c}$ and Genotyping assay (Genomic DNA was extracted from the peripheral blood.

- Second part: Three mls were loaded into a serum separating tube. The tube was kept at room temperature for 30 minutes till coagulation, and then centrifuged (at $1500 \mathrm{rpm}$ for 15 minutes). Serum was separated and the resultant serum was used for clinical chemistry tests.

- Another sample was taken 2 hours after breakfast for postprandial blood glucose assessment (PPBG).

\section{Clinical chemistry tests}

- $\quad$ FBG (mg / dl), 2 hours PPBG (mg / dl), Total Cholesterol (mg / dl), Triglyceride (mg / dl), HDL-C (mg / dl) and LDL-C (mg / dl) were performed by standard methods using Biosystem A15 (Barcelona, Spain) chemical auto analyzer by appropriate chemical principles .

- Insulin level was measured using insulin ELISA kits supplied by Prechek Bio, Inc. CA 92801, EU [9].

- Glycated haemoglobin (HbA1C) was measured by the use of HbAlc kits supplied by POINTE Scientific Canton MI. USA [10].

- Homeostasis insulin resistance model (HOMAIR) was determined as follows: fasting glucose (mg / dl) multiplied by fasting insulin $(\mu \mathrm{U} / \mathrm{ml})$ divided by $22.5[11]$.

- Quantitative insulin sensitivity test index (QUICKI) was determined as the inverse amount of fasting insulin and fasting glucose logarithms: QUICKI= 1/ [log (fasting insulin) + $\log$ (fasting glucose)] [12].
Determination of FTO (rs9939609) gene polymorphism by PCR-RFLP

- Genomic DNA was extracted from peripheral whole blood using Blood Genomic DNA Purification Mini Kit, Gene JET (Cat.\#K0781) Thermo Scientific, (EU) Lithuania according to the manufacturer instructions. ${ }^{13}$

- Genotyping of FTO gene SNP (rs9939609) was performed using polymerase chain reaction restriction fragment length polymorphism (PCRRFLP).

The isolated DNA was amplified using Dreem Taq Green PCR master mix (Thermo Scientific, Lithuania EU).

The reaction mixture was prepared as follow and added to PCR tube: $1 \mu \mathrm{l}$ of each primer, $10 \mu \mathrm{l}$ genomic DNA, $25 \mu$ l Dream Taq Green buffer and $13 \mu$ l Nuclease free water. The sequence of the primer was as follow: forword 5'AACTGGCTCTTGAATGAAATAGGATTCA GA-3' and reverse 5'AGAGTAACAGAGACTATCCAAGTGCAGT AC-3' to reach a total volume of $50 \mu 1$ per tube.

The amplification was done using step one Real Time PCR (Applied Biosystem, USA).

Thermal cycler conditions were: Initial denaturation at $95^{\circ} \mathrm{C}$ for 4 mins; 35 cycles of denaturation at $95^{\circ} \mathrm{C}$, denaturation at $94^{\circ} \mathrm{C}$ for 30 seconds, annealing at $61^{\circ} \mathrm{C}$ for 30 seconds, and extension at $72^{\circ} \mathrm{C}$ for $1 \mathrm{~min}$; and Final incubation after the last cycle at $72^{\circ} \mathrm{C}$ for $10 \mathrm{~min}$.

- The PCR fragments were digested with Restriction fast digest ScaI (Thermo Scientific, Lithuania EU) at $72{ }^{\circ} \mathrm{C}$ for $1 \mathrm{hr}$.

PCR amplified products were observed by gel electrophoresis on $1 \%$ agarose gel including ethidium bromide and visualized by UV light trans-illumination.

The 3 expected genotypes would appear as follows:

- T allele: $182 \mathrm{bp}$

- A allele:154,28bp

- A/T allele:182,154,28bp

Gel was then photographed

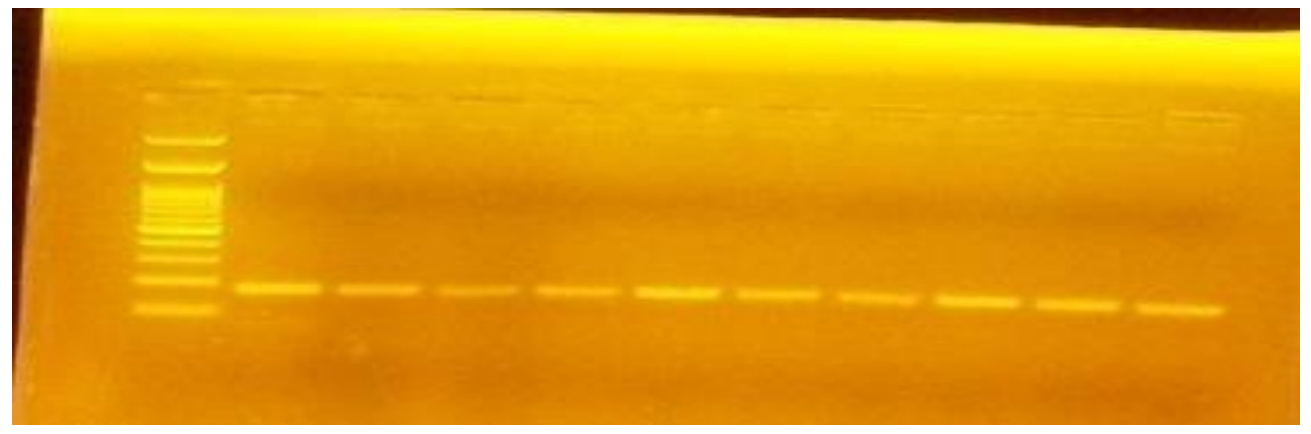

Fig (1) PCR REST. 


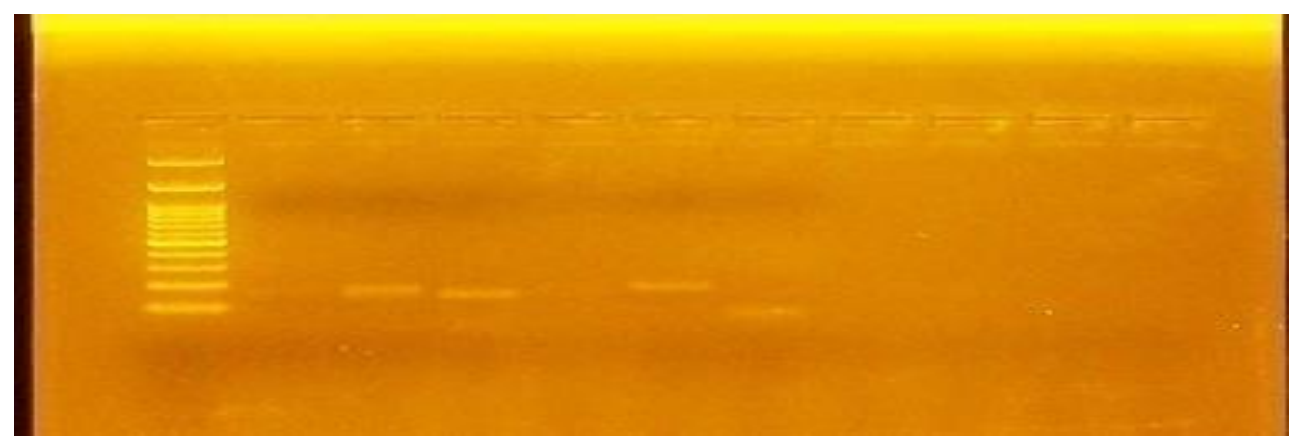

Fig (2) After rest.

\section{Statistical analysis}

Tabulate and analyze the data collected using the SPSS version16 software (SpssInc, Chicago, ILL Company). Categorical results is classified as numbers and percentages, implying quantitative data \pm standard deviation, median, and IQ Rand spectrum. Chi square (X2) or Fisher's exact test (FET) was used for categorical variables. Determined probability ratios (OR) and 95\% CI. Quantitative normality data were analyzed using Shapiro-Wilks methods, predicting normality at $\mathrm{P}>0.05$. Work student $" \mathrm{t}$ " tested distributed variables with 2 independent groups. Therefore, non-parametric variables were tested using verify Man Whitney $\mathrm{U}$. Variance was analyzed using ANOVA for parametric variables or Kruskal Wallis (KW) check. Important research on ANOVA and KW followed multiple posthoc tests to identify significant pairs using Bonferroni approaches. Conditional logistics regression research was conducted to develop the relation between FTOgene polymorphism and diabetes. The accepted standard value was 0.05 ( $\mathrm{P}<0.05$ was considered significant). Hardy-Weinberg gene polymorphism equilibrium (data not shown). OEGE-Online Genetic Epidemiology Studies Encyclopedia founded Hardy-Weinberg's balance [14].

\section{Results}

\section{Patients characteristics and laboratory findings}

Control bunch was chosen to be age and sex coordinated with patients, gathering. As per anthropometric estimations there was factually noteworthy increment in the weight, BMI, NC (guys and females), WC (guys and females) and WHR (guys and females) in diabetic patients, bunch contrasted with control gathering while there was no critical distinction in the tallness among the contemplated gatherings. FBS, HbAlc and HOMA-IR were measurably altogether raised in diabetic patients, bunch comparative with control gathering while factually critical decrease in the mean of QUICKI was seen in diabetic patients, gathering. With respect to the lipid profile, both TG and TC levels indicated noteworthy rise in diabetic patients than in the benchmark group. HDL-C mean was altogether diminished in diabetic patients, bunch than the benchmark group.
FTO (rs9939609) quality polymorphism among contemplated gathering and Binary calculated relapse investigation:

AA genotype recurrence was fundamentally higher in patients, gathering $(15 \%)$ when contrasted and the benchmark group (7.5\%). People with AA genotype were around multiple times bound to have DM than TT genotype patients $(\mathrm{OR}=6.8,95 \% \mathrm{CI}=1.7-26.6$ and $\mathrm{P}$ $<0.006$ ). An allel recurrence was essentially higher in patients, gathering $(42.5 \%)$ when contrasted with control gathering (17.5). People with An allele were 3.48 folds to have $\mathrm{DM}$ than those with $\mathrm{T}$ allele $(\mathrm{OR}=3.48$ and $95 \% \mathrm{CI}=1.68-7.21$ and $\mathrm{P}<0.001$ ) Fig (3) Table (1). Binary logistic regression analysis was done for prediction of the association of FTO gene polymorphism and type 2 diabetes. It revealed that AA and AT genotype were significant predictors of type 2 diabetes mellitus. AA was predictor of recessive model $(\mathrm{OR}=10.2 \& 95 \%$ $\mathrm{CI}=2.1-48.8 \& \mathrm{P}$ value was 0.04$)$ and AT/AA were predictors of dominant models $(\mathrm{OR}=3.0 \quad \& \quad 95 \%$ $\mathrm{CI}=1.16-7.73 \& \mathrm{P}$ value was 0.023 ) Table (2).

Association between FTO gene polymorphism and anthropometric measurements

The means of BMI, NC, WHR (in females) and WC (males) were higher in AA genotype group $(\mathrm{P}=0.005$, $\mathrm{P}=0.047, \mathrm{P}=0.001 \quad \& \quad \mathrm{P}=0.046$ respectively) when compared to TT \& AT genotype groups while, there were no significant differences in weight, height, WC (in females) or WHR (in males) among FTO genotype groups $(\mathrm{P}=0.16, \mathrm{P}=0.69, \mathrm{P}=0.18 \& \mathrm{P}=0.32$ respectively) Table (3).

Association between FTO gene polymorphism
with clinical and laboratory findings
There was no statistically significant difference in age, sex or hypertension among FTO genotype groups while there was significant increase in duration of DM and HOMA-IR in AA genotype group compared to TT \& AT genotype groups $(\mathrm{P}=0.007 \quad \& \mathrm{P}=0.022$ respectively). There was significant increase in insulin level in TT genotype group when compared to AA\& AT genotype groups $(\mathrm{P}=0.011)$ while there was no statistically significant difference in the mean of FBS, HbA1C or QUICKI among FTO genotype groups $(\mathrm{P}=0.49, \mathrm{P}=0.47 \& \mathrm{P}=0.75$ respectively).

There was statistically significant decrease in the level of HDL in AA genotype group compared to TT and 
AT genotype groups $(\mathrm{P}=0.021)$. However, there was no statistically significant difference in the levels of TG, TC or LDL among FTO genotype groups $(\mathrm{P}=0.25, \mathrm{P}=0.62 \&$ $\mathrm{P}=0.75$ respectively) Table (4).

Table (1) Comparison between the studied groups regarding FTO genotype and allele frequency.

\begin{tabular}{|c|c|c|c|c|c|c|c|}
\hline \multirow[t]{2}{*}{ Variable } & & \multicolumn{2}{|c|}{$\begin{array}{c}\text { Diabetics } \\
(n=40)\end{array}$} & \multicolumn{2}{|c|}{$\begin{array}{c}\text { Controls } \\
(n=40)\end{array}$} & \multirow{2}{*}{$\begin{array}{c}\text { OR } \\
(95 \% \mathrm{CI}) \\
\end{array}$} & \multirow[t]{2}{*}{$\mathbf{P}$} \\
\hline & & No. & $\%$ & No. & $\%$ & & \\
\hline \multirow{3}{*}{ Geno-type } & TT & 20 & 50.0 & 29 & 72.5 & Ref & \\
\hline & AT & 6 & 15.0 & 8 & 20.0 & $1.09(0.32-3.6)$ & $0.89(\mathrm{NS})$ \\
\hline & $\mathbf{A A}$ & 14 & 15.0 & 3 & 7.5 & $6.8(1.7-26.6)$ & $0.006(\mathrm{~S})$ \\
\hline \multirow[t]{2}{*}{ Allele } & $\mathbf{T}$ & 46 & 57.5 & 66 & 82.5 & Ref & \multirow{2}{*}{$<0.001(\mathrm{HS})$} \\
\hline & A & 34 & 42.5 & 14 & 17.5 & $3.48(1.68-7.21)$ & \\
\hline
\end{tabular}

Table (2) Binary logistic regression analysis for the association of FTO gene polymorphism and diabetes.

\begin{tabular}{lccccc}
\hline Variable & & \multicolumn{4}{c}{ Binary logistic regression } \\
\cline { 2 - 6 } & & $\boldsymbol{\beta}$ & $\mathbf{O R}$ & $\mathbf{9 5 \%} \mathbf{C I}$ & $\mathbf{P}$ \\
\hline Dominant model & TT & & & Reference category & \\
& AT/AA & 1.099 & 3.0 & $1.16-7.73$ & $0.023(\mathrm{~S})$ \\
Recessive model & AT/TT & & & reference category & \\
& AA & 2.32 & 10.2 & $2.1-48.8$ & $0.004(\mathrm{~S})$ \\
\hline
\end{tabular}

Table (3) Genotype frequency according to anthropometric measurements among patients group.

\begin{tabular}{lcccccccc}
\hline \multirow{2}{*}{ Variable } & \multicolumn{2}{c}{ TT(n=20) } & \multicolumn{2}{c}{$\mathbf{A T}(\mathbf{n}=\mathbf{6})$} & \multicolumn{2}{c}{ AA(n=14) } & \multirow{2}{*}{ KWT } & \multirow{2}{*}{ P value } \\
\cline { 2 - 7 } & $\begin{array}{c}\text { Mean } \pm \\
\text { SD }\end{array}$ & Range & $\begin{array}{c}\text { Mean } \pm \\
\text { SD }\end{array}$ & Range & Mean \pm SD & Range & & \\
\hline Weight(kg) & $89.5 \pm 9.43$ & $70-118$ & $90.5 \pm 2.07$ & $87-93$ & $105.7 \pm 27.18$ & $83-165$ & 3.65 & $0.16(\mathrm{NS})$ \\
Height(m) & $1.66 \pm 0.041$ & $1.59-1.73$ & $1.67 \pm 0.044$ & $1.61-1.73$ & $1.66 \pm 0.039$ & $1.61-$ & 0.72 & $0.69(\mathrm{NS})$ \\
& & & & & & 1.74 & & \\
$\mathbf{B M I}(\mathbf{k g} / \mathbf{m} 2)$ & $33.4 \pm 3.42$ & $27.3-38.3$ & $36.3 \pm 4.97$ & $31.2-42.9$ & $41.8^{*} \pm 9.30$ & $27.4-$ & 10.7 & $0.005(\mathrm{~S})$ \\
& & & & & & 58.5 & & \\
$\mathbf{N C}_{\text {Males }}(\mathbf{c m})$ & $35.1 \pm 0.19$ & $34.9-35.4$ & $35.8^{*} \pm 0.28$ & $35.6-36$ & $35.9^{*} \pm 0.21$ & $35.7-36$ & 6.13 & $0.047(\mathrm{~S})$ \\
$\mathbf{N C}_{\text {Females }}(\mathbf{c m})$ & $31.6 \pm 1.14$ & $30-35$ & $31.75 \pm 0.95$ & $31-33$ & $32.6^{*} \pm 1.28$ & $31.5-36$ & 6.19 & $0.045(\mathrm{~S})$ \\
$\mathbf{W C}_{\text {Males }}(\mathbf{c m})$ & $95.2 \pm 3.11$ & $92-99$ & $99.5 \pm 0.70$ & $99-100$ & $101.5^{*} \pm 0.70$ & $101-102$ & 6.14 & $0.046(\mathrm{~S})$ \\
$\mathbf{W C}_{\text {Females }}(\mathbf{c m})$ & $84.4 \pm 3.66$ & $80-88$ & $85.5 \pm 2.64$ & $82-90$ & $87.0 \pm 1.95$ & $83-90$ & 3.36 & $0.18(\mathrm{NS})$ \\
$\mathbf{W H R}_{\text {Males }}$ & $0.95 \pm 0.03$ & $0.92-1.0$ & $0.98 \pm 0.00$ & $0.98-0.98$ & $0.99 \pm 0.01$ & $0.99-1.0$ & 2.23 & $0.32(\mathrm{NS})$ \\
$\mathbf{W H R}_{\text {Females }}$ & $0.83 \pm 0.022$ & $0.8-0.87$ & $0.88 \pm 0.074$ & $0.83-0.99$ & $0.92^{*} \pm 0.065$ & $0.83-1.0$ & 14.05 & $0.001(\mathrm{H}$ \\
& & & & & & & & \\
\hline
\end{tabular}

$\mathrm{KWT} \rightarrow$ Kruskal Wallis test

$* \rightarrow$ Significant in comparison with TT.

Table (4) Genotype frequency according to duration of DM and lab findings among patients group.

\begin{tabular}{|c|c|c|c|c|c|c|c|c|}
\hline \multirow[b]{2}{*}{ Variable } & \multicolumn{2}{|c|}{ TT (n=20) } & \multicolumn{2}{|c|}{$\mathrm{AT}(\mathrm{n}=6)$} & \multicolumn{2}{|c|}{$\mathrm{AA}(\mathrm{n}=14)$} & \multirow[b]{2}{*}{ KWT } & \multirow[b]{2}{*}{$p$ value } \\
\hline & Mean \pm SD & Range & Mean \pm SD & Range & $\begin{array}{c}\text { Mean } \pm \\
\text { SD }\end{array}$ & Range & & \\
\hline Duration of DM & $4.40 \pm 2.23$ & $1-9$ & $6.66 \pm 3.88$ & $3-12$ & $\begin{array}{c}8.35^{*} \pm \\
3.71\end{array}$ & $4-15$ & 10.6 & $0.007(\mathrm{~S})$ \\
\hline FBSMg/dl & $8.35 \pm 3.71$ & $102-314$ & $218.6 \pm 57.2$ & $150-300$ & $\begin{array}{c}221.8 \pm \\
62.6\end{array}$ & $132-324$ & 1.39 & $0.49(\mathrm{NS})$ \\
\hline HbA1C\% & $7.0 \pm 1.20$ & $5.8-10.2$ & $7.3 \pm 1.44$ & $6.1-9.9$ & $7.6 \pm 1.57$ & $5.9-10.9$ & 1.51 & $0.47(\mathrm{NS})$ \\
\hline Insulin & $19.6 \pm 16.59$ & $\begin{array}{l}0.29- \\
56.1\end{array}$ & $3.2 \pm 4.82$ & $\begin{array}{l}0.15- \\
12.4\end{array}$ & $\begin{array}{l}16.8 \pm \\
17.79\end{array}$ & $2.31-58.7$ & 9.0 & $0.011(\mathrm{~S})$ \\
\hline HOMA-IR & $4.68 \pm 3.8$ & $0.1-11.0$ & $4.95 \pm 4.70$ & $0.1-12.5$ & $11.3^{*} \pm 7.6$ & $1.9-21.7$ & 7.6 & $0.022(\mathrm{~S})$ \\
\hline QUICKI & $0.34 \pm 0.10$ & $\begin{array}{c}0.25- \\
0.59\end{array}$ & $0.31 \pm 0.05$ & $\begin{array}{c}0.27- \\
0.39\end{array}$ & $0.30 \pm 0.03$ & $0.25-0.37$ & 0.57 & 0.75 (NS) \\
\hline TG (mg/dl) & $149.6 \pm 42.1$ & $99-215$ & $168.1 \pm 51.7$ & $114-245$ & $\begin{array}{c}178.1 \pm \\
54.6\end{array}$ & $102-256$ & 2.72 & $0.25(\mathrm{NS})$ \\
\hline
\end{tabular}


Table (4) Continue

\begin{tabular}{lcccccccc}
\hline TC (mg/dl) & $194.4 \pm 29.3$ & $148-238$ & $203.1 \pm 30.4$ & $176-243$ & $\begin{array}{c}207.0 \pm \\
41.0\end{array}$ & $147-256$ & 0.93 & $0.62(\mathrm{NS})$ \\
HDL (mg/dl) & $49.7 \pm 7.63$ & $38-65$ & $43.3 \pm 9.11$ & $34-56$ & $\begin{array}{c}41.7^{*} \pm \\
8.65\end{array}$ & $32-56$ & 7.71 & $0.021(\mathrm{~S})$ \\
LDL (mg/dl) & $113.9 \pm 36.6$ & $64-165$ & $121.5 \pm 48.9$ & $65-172$ & $\begin{array}{c}124.7 \pm \\
32.7\end{array}$ & $63-159$ & 0.57 & $0.75(\mathrm{NS})$ \\
\hline
\end{tabular}

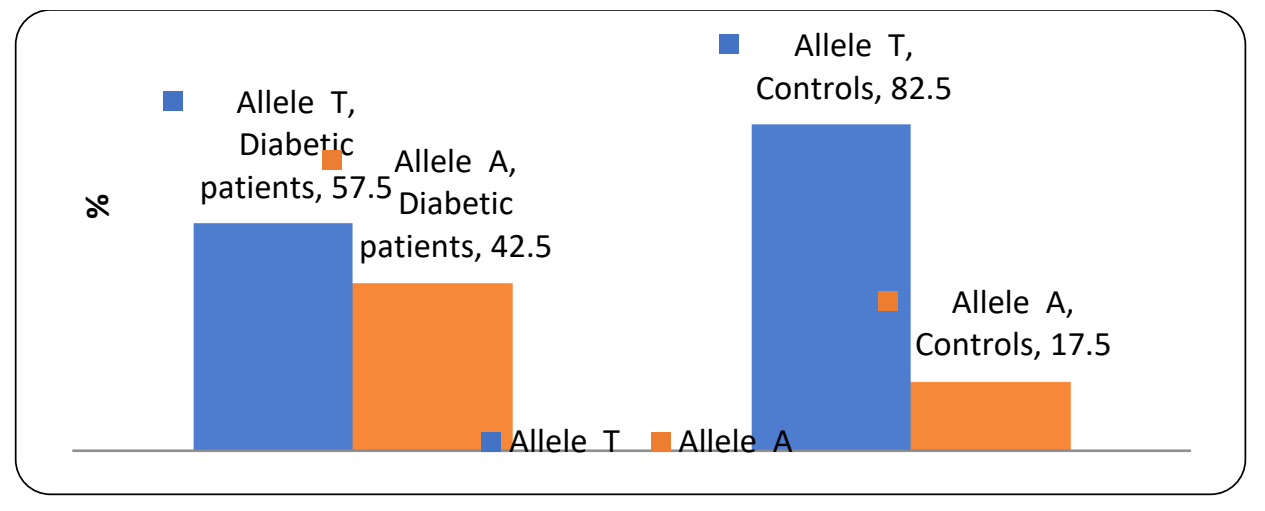

Fig (3) Bar charts showing FTO allele frequency among the studied groups.

\section{Discussion}

Diabetes mellitus is an intricate, interminable disease requiring persistent clinical consideration with multi-factorial hazard decrease systems past glycemic control [15].

Heftiness is one of the most well-known issues around the world, influencing people everything being equal, races, genders, social and social situations and giving the inclination to a progression of serious difficulties and co-morbidities, for example, type 2 diabetes mellitus, hepatic steatosis, hypertension, cardiovascular ailment, stroke, atherosclerosis, embolism and cancer [16].

For its job in beginning stage of stoutness, the FTO quality was first recognized in a genome-wide affiliation investigation (GWAS) and GWAS found that different variations of FTO (fat mass and corpulence connected quality) were associated with Body Mass Index (BMI) in various populaces. Single nucleotide polymorphisms (SNPs) found in FTO's first intron demonstrated most noteworthy connection with obesity[17].

This examination looked to show the association between fat-mass and weight related quality (FTO) polymorphisms with type 2 diabetes (T2D) and various parts of BMI in Egyptian members.

In the current investigation HOMA-IR and HbA1C demonstrated measurably critical increment in diabetic patients, bunch contrasted with control gathering while, QUICKI was altogether diminished in diabetic patients, bunch contrasted with control gathering.

These outcomes were upheld by an investigation by 18 who recorded that HOMA-IR builds the pervasiveness of metabolic condition (MS), which rose as a significant pathophysiological impact being developed of numerous non-transmittable illnesses, for example, T2DM.
Al-Sharif [19] expressed that IR by estimated HOMA and QUICKI strategies were found in the scope of 87.5 to $90 \%$ of patients with type $2 \mathrm{DM}$ and 12.5 to $22.5 \%$ of control gathering.

C.K. Roberts [20] revealed that hefty T2DM patients demonstrated essentially lower estimations of QUICKI and higher Homeostasis System Assessment-Insulin Resistance (HOMA-IR) than controls. Type 2 DM (T2DM) is a complex, polygenetic inherited ailment related with both heritable and ecological components. Insulin obstruction (IR) is a significant pathophysiological factor in the turn of events and movement of DM, and IR is additionally apparent in an assortment of metabolic sicknesses, for example, stoutness, hypertension and dyslipidemia [21]. Epidemiological investigations have demonstrated that about $25 \%$ of the populace has IR and that the predominance of IR is over $80 \%$ in patients with T2DM [22].

Our outcomes demonstrated that insulin level was fundamentally expanded in TT genotype bunch when contrasted and AA and AT genotype gatherings while HOMA-IR was progressively unmistakable in AA genotype gathering.

Critical connection was found between FTO quality polymorphism and IR in the examination of [23] Their investigation indicated that members with An allel had $\sim 2.6$ crease higher hazard to T2D. Also, $23 \%$ of the people with a higher HOMA file considered as moderate or extreme IR had An allele.

In a rs9939609 SNP balanced examination, insulin levels and HOMA levels were high in AA genotype [24].

Relative insights of the current investigation uncovered no noteworthy contrasts in the glycemic state or in the lipid profile among FTO genotype gatherings. 
Study demonstrated the relationship of FTO An allele with higher FBS in recently analyzed T2D patients $(\mathrm{P}=0.0001)$ [ 23].

As with respect to lipid profile, the outcomes indicated critical diminishing in the degree of HDL in AA genotype bunch contrasted with TT and AT genotype gatherings however there was no measurably huge distinction in the degrees of TG, TC or LDL among FTO genotype gatherings.

M. Mohamed [25] bolstered our outcomes in regards to lipid profile demonstrating non-noteworthy FTO inconstancy communication with all lipid profiles while [24] found that just TG indicated critical varieties between the three genotypes with the most noteworthy TG mean in the TA genotype.

As respect lipid profile, the current investigation demonstrated that there was factually critical increment in TG and TC levels and diminishing in HDL level in diabetic patients, bunch when contrasted with control gathering. While, there was no measurably noteworthy distinction in the mean of LDL levels among the considered gatherings.

This goes in accordance with an examination by 26 which uncovered a critical increment in the methods for the serum levels of all out cholesterol and a noteworthy decrease in the serum levels of HDL among diabetic gathering when contrasted and the benchmark group.

Hyperglycemia and significant levels of T2DMrelated IR effectsly affect fat digestion, coming about in atherogenic dyslipidemia portrayed by lipoprotein deserts, raised extremely low thickness lipoprotein cholesterol (VLDL), raised low thickness lipoprotein cholesterol (LDL-c), raised triacylglycerol (TAG) and lower high thickness lipoprotein cholesterol (HDL-c) [27].

On looking at anthropometric estimations between contemplated bunches a measurably noteworthy increment was found as with respect to the weight and BMI, NC (guys and females),WC (guys and females) and WHR (guys and females) in diabetic patient gatherings when contrasted with control gatherings.

These outcomes were upheld by another past investigation by [28] That stated, the BMI change expanded the relationship of type 2 diabetes in Aotearoa/New Zealand. What's more, by an audit [29] that demonstrated diabetes was related with expanded BMI. Be that as it may, 30found no critical contrasts among diabetic and non-diabetic people as respect BMI.

T2D pathophysiology is related with expanded fat mass31, and Insulin obstruction associates with corpulence even inside the ordinary range. Fat tissue assumes a significant job in controlling the vitality balance by lipid stockpiling and emission and by being a functioning endocrine organ emitting adipokines that impact foundational metabolism [32]. Insulin obstruction is related with instinctive and subcutaneous fat content [33].

Likewise, these outcomes go in accordance with the examination by.34who detailed that Neck boundary (NC) is a marker of chest area subcutaneous fat tissue, and may speak to extra metabolic hazard factors free of focal adiposity. It has so far been related with type 2 diabetes mellitus (T2DM). Studies have uncovered that neck periphery (NC), as a file of chest area subcutaneous fat tissue conveyance, is a decent apparatus to recognize overweight and obesity.35And it is related with cardiometabolic dangers (CMR) past that of BMI and WC. Neck outline estimation is anything but difficult to perform, speedy, dependable, and cheap. Likewise, its estimation is advantageous and not influenced by the previously mentioned factors that impact WC estimation [36].

PCR and limitation piece length polymorphism (RFLP) were tried for FTO qualities polymorphisms. The outcomes indicated that AA patients were around multiple times bound to have DM than TT patients. People with An allele were 3.48 folds to have DM than those with $\mathrm{T}$ allele.

Xiao et al.37 bolstered these discoveries as they exhibited that the genotype circulations of locus rs9939609 in the FTO quality contrasted fundamentally between the diabetes and control gatherings, suggesting that these polymorphisms are related with $\mathrm{T} 2 \mathrm{D}$ in Uyghurs. Furthermore, that Uyghurs with locus rs9939609 containing allele A have an expanded danger of T2D.

Double calculated relapse examination was accomplished for forecast of the relationship of FTO quality polymorphism and type 2 diabetes. It uncovered that AA and AT genotype were huge indicators of type2 diabetes mellitus. AA genotype was an indicator of passive model $(\mathrm{OR}=10.2$ and $95 \% \mathrm{CI}=2.1-48.8$ and $\mathrm{P}$ esteem was 0.04) and AT/AA genotypes were indicators of prevailing models $(\mathrm{OR}=3.0$ and $95 \%$ $\mathrm{CI}=1.16-7.73$ and $\mathrm{P}$ esteem was 0.023$)$. $\mathrm{T}$ allele is a defensive factor yet An allele is a free hazard factor for type 2 diabetes. People with AA genotype $(\mathrm{OR}=6.8)$ were around multiple times bound to have DM than TT patients.

These outcomes go in accordance with examines performed by $[38,39]$ who recorded relationship of homozygous AA genotype rs9939609 with a higher danger of type 2 diabetes mellitus.

Also,. S A. Scuteri [40] consider that FTO rs9939609 was emphatically associated with T2DM in Palestine. The relationship of the FTO variation rs9939609 with T2DM was incompletely weakened by representing BMI with an exceptional proportion of $1.84 .95 \%$ CI $(1.04-3.05) \mathrm{p}=0.03$, proposing that the FTO-T2DM relationship was not totally managed by the FTO variation impact on BMI.

A L Younus [41] clarified that FTO-quality polymorphism can be a hazard factor for T2DM as it is related with stoutness.

On the other hand,. S Al-Sinani [42] announced that nearness of T allele in FTO quality polymorphisms in SNPs rs9939609 was related with expanded danger of creating T2DM in hefty Iraqis. In T2DM, the small allele (T) for rs9939609 was essentially higher $(31.25 \%)$ comparative with the objective stout populace 
(20\%) $(\mathrm{P}=0.0001)$. The homozygous genotype (TT) expanded the danger of T2DM.

Utilizing paired calculated relapse investigation by 43 a.44 there was no connection between's FTO variations (rs9939609) and T2D danger.

A 2007 genome-wide affiliation investigation (GWAS) expressed that the weight file (BMI) influence rs9939609 change inside the primary intron of the FTO quality inclines European populaces to diabetes through an impact on weight file (BMI) [45].

To more readily clarify the impact of FTO quality polymorphism on anthropometric estimations, AA genotype bunch indicated measurably noteworthy increment in the BMI, WHR (in females), NC and WC (in guys) when contrasted with TT and AT genotype gatherings.

In concurrence with our results.46 exhibited that people with the FTO hazard allele (An) and low physical action had fundamentally high stoutness chance variables (increment in BMI, WC, NC, WHR and bodyweight).

Additionally, another study47 announced that subjects with AA genotype had higher BMI and WC contrasted with TA and TT transporters.

On the other hand,.48 detailed no significant relationship among's rs9939609 and heftiness in individuals of various ethnicity, including an investigation indicating that Mexicans with rs9939609 variations exhibited no association between these SNPs and stoutness.

FTO is exceptionally communicated in the nerve center area of the mind, which is associated with guideline of food admission an.

\section{Conclusions}

In conclusion, AA and AT genotypes are significant predictors of type 2 diabetes mellitus and individuals with AA genotype were about seven times more likely to have DM than TT patients. There was significant correlation between anthropometric measurements [BMI, NC, WHR (in females) and WC (males)] and AA genotype. These results support the involvement of the rs9939609 (A/T) FTO in T2D and obesity vulnerability and may have significant scientific and therapeutic consequences.

\section{Recommendations}

More genetic and functional research in FTO variants can help clarify the physiological mechanisms by which they influence T2D pathogenesis and enhanced BMI.

\section{References}

[1] D.L. Waters, A.L. Villareal D.T. Ward, Weight loss in obese adults 65 years and older: a review of the controversy. ExpGerontol, Vol. 48, PP.1054$61,2013$.
[2] T. Kellyang, C.S. Chen, K. Reynolds , Global burden of obesity in 2005 and projections to 2030. Int J Obes (Lond), Vol.32, PP.1431-1437, 2008.

[3] M.F. Bouchonville , D.T. Villareal , Sarcopenic obesity: how do we treat it? CurrOpinEndocrinol Diabetes Obes, Vol. 20, PP.412-419, 2013.

[4] Y.I. Sanchez-Zamora, The role of MIF in Type2 Diabetes Mellitus. J of Diabetes Research, Vol. 19, PP.6, 2007

[5] S. Tanaka, M. Honda, B. Wu , Clinical features of normal weight Japanese patients with type 2 diabetes who had formerly been obese. J AtherosclerThrombm, Vol. 18, PP. 115-21,2011.

[6] T.M. Frayling, N.J. Timpson, Weedon MN , A common variant in the FTO gene is associated with body mass index and predisposes to childhood and adult obesity, Vol.316, PP.889-894,2007.

[7] S.T. Raza, S. Abbas, Z. Siddiqi , Mahdi F (). Association between ACE (rs4646994), FABP2 (rs1799883), MTHFR (rs1801133), FTO (rs9939609) genes polymorphism and type 2 diabetes with dyslipidemia. Int $\mathbf{J}$ Mol Cell Med, Vol. 6(2)PP.121,2017.

[8] A. Moleres, M.C. Ochoa, Rendo-Urteaga T Dietary fatty acid distribution modifies obesity risk linked to the rs9939609 polymorphism of the fat mass and obesity-associated gene in a Spanish case-control study of children. Br J Nutr, Vol.107(4)PP.533-8. 2012

[9] A. Kyventidis, G. Tzimagiorgis , T. Didangelos. Peripheral blood monocytes can differentiate into efficient insulin-producing cells in vitro. Hippokratia. 2015 Oct-Dec , Vol.19(4)PP.34451,2015 .

[10] D.M. Nathan, D.E. Singer, K.M. Anderson, Wilson WF and Evans JC Diabetes 1992 Feb, Vol. 41(2)PP. 202-208,1992.

[11]D.R. Matthews, J.P. Hosker, A.S. Rudenski, Naylor BA, Treacher DF and Turner RC (1995). Diabetologia. 1985 Jul;28(7):412-9.

[12] Katz A, Nambi SS, Mather K, Baron AD, Follmann DA, Sullivan G, Quon MJ.J et al., (2000) Clin Endocrinol Metab. $2000 \mathrm{Jul} ; 85(7): 2402-10$.

[13] N.R. Rodriguez, N.M. DiMarco S. Langley; American Dietetic Association (2009); Dietitians of Canada; American College of Sports Medicine: Nutrition and Athletic Performance.J Am Diet Assoc. Mar , Vol.109(3), PP.509-27,2009.

[14] American Diabetes Association , Diagnosis and classification of diabetes mellitus. Diabetes Care, Vol.38(1), PP.S8-S16,2015.

[15] G. Turconi, H. Cena, D. Bagchi , Epidemiology of obesity Epidemiology, Pathophysiology and Prevention. Second edition. USA: CRC Press, Vol. 2013. PP. 3-33, 2013.

[16] S.S. Abdelmajed, M. Youssef , M.E. Zaki , Association analysis of FTO gene polymorphisms and obesity risk among Egyptian children and adolescents. Genes Dis, Vol. 4(3), PP.170-175,2017. 
[17] G.R. Yang, S.Y. Yuan , H.J. Fu , Neck circumference positively related with central obesity, overweight, and metabolic syndrome in Chinese subjects with type 2 diabetes: Beijing Community Diabetes Study 4. Diabetes Care,Vol.33(11), PP. 2465-7,2010.

[18] H. Yilmaz (): 1Sivas State Hospital, Dep. of Internal Medicine, Sivas - 2Cukurova University Medical Faculty, Dep. of Internal Medicine, Acta Medica Mediterranea, Vol.31, PP. 143,2015.

[19] Al-Sharif , M. Fadwa , European Journal of General Medicine ,Vol. 13 (4), pp91-96, 2016.

[20]C.K. Roberts, A.L. Hevener , R.J. Barnard (): Metabolic syndrome and insulin resistance: Underlying causes and modification by exercise training. Compr Physiol ,Vol. 3, PP.1-58,2013.

[21]M. Zhang, T. Hu, S. Zhang , Associations of different adipose tissue depots with insulin resistance:A systematic review and meta-analysis of observational studies. Sci Rep , Vol. 5, PP.18495, 2015.

[22] A. Khoshi, M.K. Bajestani , H. Shakeri, Association of Omentin rs2274907 and FTO rs9939609 gene polymorphisms with insulin resistance in Iranian individuals with newly diagnosed type2 diabetes. Lipids Health Dis, Vol.18, PP.142,2019

[23] M Majdi , N Mohammadzadeh , H Lotfi , Diabetes and Metabolic Syndrome: Clinical Research and Reviews, Vol. 25 ( 5), PP. 312-317, 2013.

[24] A. Shahid, S. Rana, S. Saeed, Common variant of FTO gene, rs9939609, and obesity in Pakistani females. Biomed Res Int, vol . 25, PP. 214220,2013.

[25] M. Mohamed Hani (): Saudi J Biomed Res, Vol. 4(10), PP. 338-348,2019.

[26]B. Biadgo, S. Abebe, H. Baynes , Correlation between serum lipid profile with anthropometric and clinical variables in patients with type 2 diabetes mellitus. Journal Home, Vol 27( 3) , PP. 215-226, 2017.

[27] R,L. Minster, N. Land Hawley, C.T. Su , A thrifty variant in CREBRF strongly influences body mass index in Samoans. Nat Genet, Vol.48, PP.10491054, 2016.

[28] V, Lorenzo, M , Martin , M. Rufino High prevalence of overweight in a stable Spanish hemodialysis population: a cross sectional study. J RenNutr., Vol.13(1), PP.52-9,2003.

[29]Z. Huang, M. Dong, J. Li, Meta-Analysis of theassociation of IGF2BP2gene rs4402960 polymorphisms with T2DM in Asia. BIO Web of Conferences, Vol.8(2). PP.20-30, 2017.

[30] T. Fleming, M. Robinson, B. Thomson, Global, regional, and national prevalence of overweight and obesity in children and adults during 1980-2013: a systematic analysis for the Global Burden of Disease Study, Vol. 20,PP. 766-781. 2014.

[31] T. Romacho, M. Elsen, D. Rohrborn , Adipose tissue and its role in organ crosstalk. Acta Physiologica, Vol. 210, PP. 733-753, 2014.
[32] S. Ambady, C. Malcuit, O. Kashpur, Expression of NANOG and NANOGP8 in a variety of undifferentiated and differentiated human cells , Vol.54(11-12), PP.1743-54.

[33]A. Papazafiropoulou, K Anagnostopoulou, N. Papanas, Rev Diabet Stud. Winter, Vol.13(4), PP. 215-216,2016.

[34]M. Saka, P. Türker, A. Ercan , Is neck circumference measurement an indicator for abdominal obesity? A pilot study on Turkish Adults. Afr Health, Vol.14, pp,570-575,2014.

[35] J.Y. Zhou, H. Ge, M.F. Zhu, Neck circumference as an independent predictive contributor to cardiometabolic syndrome. Cardiovasc Diabetol, Vol.12, PP.76,2013.

[36] S. Xiao, X. Zeng , Y. Fan , Gene Polymorphism Association with Type 2 Diabetes and Related Gene-Gene and Gene-Environment Interactions in a Uyghur Population. Med SciMonit, vol . 22, PP.47487, 2016.

[37] S.T. Raza, S. Abbas, Z. Siddiqi , Int J Mol Cell Med, Vol. 6(2), PP.121-130,2017.

[38] V Legry, D Cottel , J. Ferrières , Effect of FTO polymorphism on fat mass, obesity, and type 2 diabetes mellitus in the French MONICA Study. Metabolism, Vol.58(7):971-5, 2009.

[39] A. Sabarneh, S. Ereqat, S Cauchi, Common FTO rs9939609 variant and risk of type 2 diabetes in Palestine.BMC Med Genet, vol , 31, PP.19(1):156,2018.

[40] S A. Scuteri, W.M. Sanna Genome-wide association scan shows genetic variants in the FTO gene are associated with obesity-related traits, Vol.3(7),PP. 315-33,2007

[41] A L Younus, M Algenabi, Department of Internal Medicine, College of Medicine, Kufa University, Najaf, Ira, Vol. 26, PP. 60 ,2017

[42] S Al-Sinani, N Woodhouse, A Al-Mamari, World J Diabetes. Mar, Vol.156(2),pp,358-66,2015.

[43]B.J. , Hennig A.J. Fulford, G. Sirugo , Med Genet. 2009 Mar 19; 10(11):21.

[44] Frayling TM, B.M.C Timpson, Weedon, Zeggini E, Freathy RM and Lindgren CM A common variant in the FTO gene is associated with body mass index and predisposes to childhood and adult obesity. Science, vol .25(4), PP. 889-894, 2014.

[45]B. Oyeyemi, C . Ologunde , N. Alamukii , Integrative Biology Unit, Transcriptional Regulation Group, International Centre for Genetic Engineering and Biotechnology, New Delhi, India. Journal of Obesity Volume, vol . 30 ( 3), PP. 312-316, 2017.

[46] M. Khella , M .Hamdy , A. Amin BMC Medical Genetics BMC series - open, inclusive and trusted Vol. 18, PP. 101,2017

[47] A .Abadi, J. Peralta-Romero , F. Suarez ,Assessing the effects of 35 European-derived BMI-associated SNPs in Mexican children Obesity, Vol. 24 (9), PP. 415-420,2016.

[48] R. Larder, M.K. Cheung, Y.C. Tung, Yeo GS and Coll AP ,Vol.22(2),PP.53-9,2011. 
